\title{
Poly (Ethylene Glycol-Co-Styrene) Films Deposited by Plasma Polymerization Reactions at Atmospheric Pressure
}

\author{
Mihai Asandulesa, George Rusu, Ionut Topala*, Valentin Pohoata, Marius Dobromir and \\ Nicoleta Dumitrascu
}

Faculty of Physics, Alexandru Ioan Cuza University, Bd. Carol No. 11, 700506, Iasi, Romania

\begin{abstract}
Atmospheric pressure plasma co-polymerization of ethylene glycol and styrene was applied to produce poly (ethylene glycol-co-styrene) using a dielectric barrier discharge. The chemical structure of polymerized films was studied by Fourier-transform infrared spectroscopy which confirms that we obtained copolymerized films with hydroxyl groups incorporated. Chemical composition of films was studied by X-ray Photoelectron Spectroscopy and oxygen containing groups $(\mathrm{C}-\mathrm{O}$ and $\mathrm{C}=\mathrm{O})$ were identified. Topography of polymer films was revealed using Atomic Force Microscopy technique and the film root mean square roughness $\left(\mathrm{R}_{\mathrm{rms}}\right)$ was found to be $1.6 \mathrm{~nm}$. Surface wettability was analyzed using water contact angle technique.
\end{abstract}

Keywords: Plasma polymerization, atmospheric pressure, poly (ethylene glycol-co-styrene), thin films.

\section{INTRODUCTION}

It is known that nonspecific proteins interactions with implants surface are leading to medical complications. In recent years, considerable studies have been made to obtain new polymeric materials that can be used to coat implant's surface [1]. In this case, the polymeric film acts as an intermediary agent in the interaction pathways between implants and protein containing biological solutions. One of the most efficient procedures to develop new protein resistant surfaces is the use of plasma polymerization [2]. Plasma polymerization process refers to formation of thin polymer films by fragmentation of organic compounds into radicals and their recombination during film growth [3-6]. Due to the unique properties such as good adhesion to substrates, highly cross-linked layers and controlled thickness at nanoscale [7] the plasma polymerized films are becoming increasingly important for a wide range of applications, from functional coatings for biomolecules immobilization [8] to dielectric materials in microelectronics and nanoelectronics.

Polyethylene glycol-type polymerized films are widely used in order to minimise the protein adsorption and also cell adhesion onto different substrates [9-12]. A disadvantage of these films is the low stability in aqueous solutions. Copolymerization of various monomer mixtures represents a convenient way to obtain thin polymers films with imposed surface properties. Thus, plasma co-polymerized films of ethylene glycol in a hydrophobic matrix, derived from styrene molecules provides a good solution to assure water stability and preserve the functional groups of ethylene glycol.

*Address correspondence to this author at the Faculty of Physics, Alexandru Ioan Cuza University of Iasi, 11 Carol I Boulevard, 700506, Iasi, Romania; Tel: +40-232-201-188; Fax: +40-232-201-150;

E-mail: ionut.topala@uaic.ro
The aim of this work was to obtain poly(ethylene glycolco-styrene) (ppES) films by plasma polymerization processes from a gaseous mixture of styrene and ethylene glycol as monomers. Thin films were deposited using a dielectric barrier discharge working at atmospheric pressure. Detailed analyses of polymerized films were performed by Fourier-transform infrared spectroscopy (FTIR), UV-Vis spectroscopy, X-ray photoelectron spectroscopy (XPS), atomic force microscopy (AFM) and water contact angle measurements.

\section{EXPERIMENTAL SET-UP}

The experimental arrangement of discharge consists of two parallel-plane copper electrodes separated by a glass dielectric barrier (Fig. 1). The electrodes diameter is $30 \mathrm{~mm}$ and discharge gap is fixed at $5 \mathrm{~mm}$. Helium (spectral purity of $99.999 \%$ ) is introduced into the discharge chamber using the flowmeter 1 at a constant rate of $3 \mathrm{~L} / \mathrm{min}$. Liquid precursors were introduced into the discharge by gas bubbling using the flowmeter 2 (helium as carrier gas, with a rate of $0.5 \mathrm{~L} / \mathrm{min}$ ). The residual gas is flowing from the discharge chamber through an exhaust system without supplementary pumping systems.

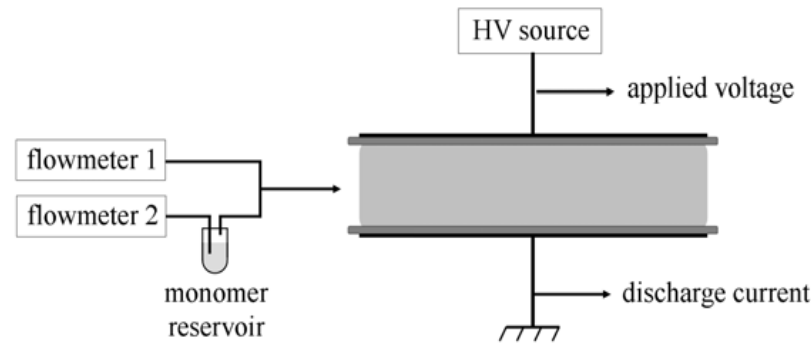

Fig. (1). Diagram of the experimental set-up.

Atmospheric pressure plasma was generated with high voltage pulses supplied by a digital waveform generator (Tabor 
electronics WW5064) and a high voltage amplifier (Trek model PD 07016). The discharge is driven by high voltage square pulses with $6 \mathrm{kV}$ amplitude and $260 \mu$ s length. The discharge operates in the glow mode at atmospheric pressure and the current value is fixed at $50 \mathrm{~mA}$.

\section{MATERIALS AND METHODOLOGY}

The organic precursors used to obtain plasma copolymerized films were styrene and ethylene glycol. Styrene (from Sigma Aldrich) with $>99.9 \%$ purity was used in order to obtain a polymer matrix and ethylene glycol with $>99.5 \%$ purity was used to attach to the styrene matrix hydroxyl type functional groups. A mixture with $75 \%$ ethylene glycol and $25 \%$ styrene was prepared to fill the monomer reservoir as presented in Fig. (1).

The chemical structure of films was investigated by Fourier-transform infrared spectroscopy. IR transmission spectra were recorded using a Bomem MB-Series 104 spectrometer in the range of $4000-400 \mathrm{~cm}^{-1}$ and $4 \mathrm{~cm}^{-1}$ resolution. The FTIR spectra were analyzed using Grams Galactic software.

In order to verify absorption properties of our films, the $\mathrm{UV}-\mathrm{V}$ is spectra were recorded in the range of 400-200 nm, using a Perkin-Elmer Lambda3 spectrophotometer.

Chemical composition of films was obtained from analysis of polymer XPS spectra. XPS analysis was performed with a 5000 VersaProbe (Physical Electronics) spectrometer, equipped with a monochromatic $\mathrm{Al} \mathrm{K}_{\alpha} \mathrm{X}$-ray source $(\mathrm{hv}=1486.7 \mathrm{eV})$. During measurements, the pressure in the analysis chamber was $5.9 \times 10^{-8} \mathrm{~Pa}$ and the photoelectron takeoff angle relative to the surface was $45^{\circ}$. The binding energy was calibrated by the peak energy of $\mathrm{C} 1 \mathrm{~s}$ $(285 \mathrm{eV})$ as reference.

Information about polymer films topography were acquired by means of Atomic Force Microscopy (AFM) technique. The AFM images were obtained using a NTMDT Solver Pro-M type apparatus. Moreover, the analysis was performed in tapping mode with $0.1 \mathrm{~nm}$ resolution in $\mathrm{z}$ direction using a standard silicone nitride tip (NSC21) with a typical tip radius of $10 \mathrm{~nm}$.

The wettability of plasma films was analyzed using contact angle measurements. A horizontal optical microscope with a digital camera attached was used to visualize water drops $(2 \mu \mathrm{L}$ of volume) deposited onto the polymer surfaces. Contact angle values were obtained from images analysis using appropriate software for drop shape recognition.

The thickness of plasma polymerized films was determined by an interferometric method. After 10 minutes of plasma polymerization, polymer films with a thickness of about $800 \mathrm{~nm}$ were obtained using the electrical parameters mentioned above.

\section{RESULTS}

\section{a. FTIR Spectra Analysis}

Comparative FTIR spectra of plasma polystyrene, polyethylene glycol and ppES films in the region $1750-700 \mathrm{~cm}^{-1}$ are shown in Fig. (2a). The characteristic FTIR spectrum of polystyrene films contains signatures of aromatic and aliphatic (a)

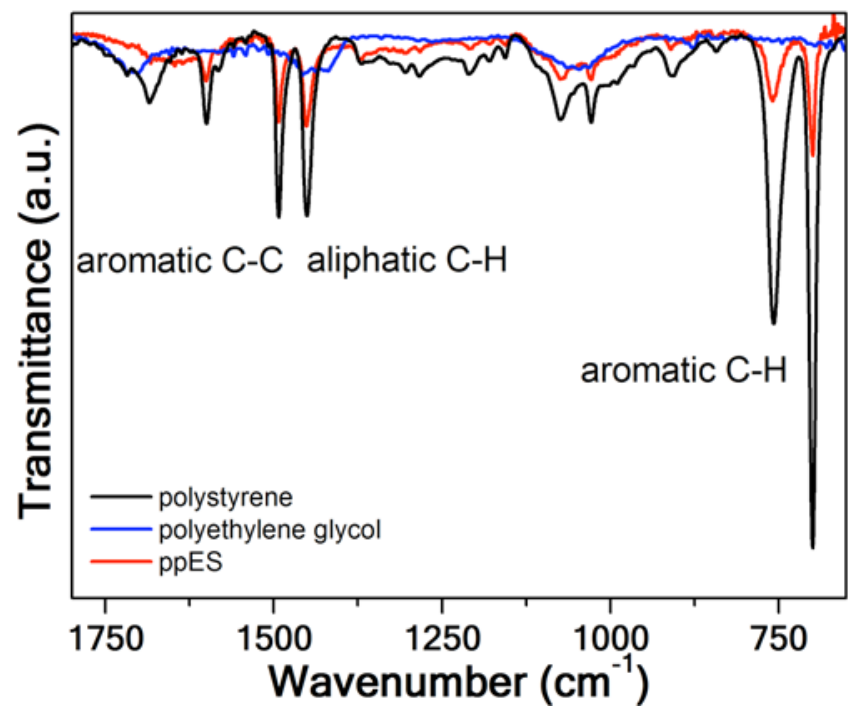

(b)

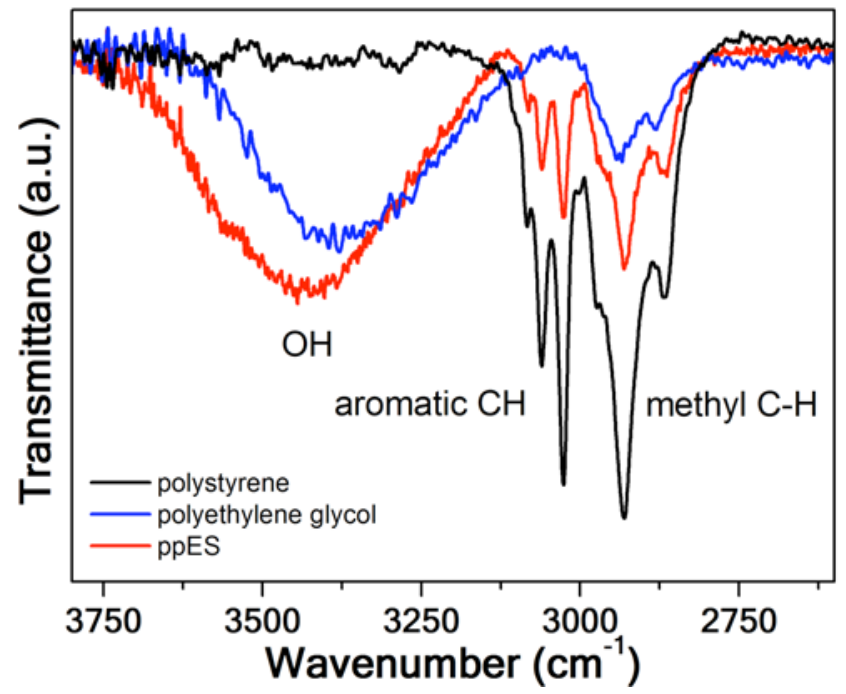

Fig. (2). Comparative infrared spectra of plasma polystyrene, polyethylene glycol and ppES films.

$\mathrm{C}-\mathrm{H}$ groups, while the spectrum of polyethylene glycol films contains signatures from hydroxyl groups and aliphatic C-H groups. The ppES spectrum contains aromatic $\mathrm{C}-\mathrm{H}$ groups with signatures at 700, 757 and $909 \mathrm{~cm}^{-1}, \mathrm{C}-\mathrm{H}$ in-plane deformation bending of aromatic ring at 1073 and $1029 \mathrm{~cm}^{-1}$, the methyl C-H bending at $1450 \mathrm{~cm}^{-1}$ and the aromatic $\mathrm{C}=\mathrm{C}$ stretching at 1683 , 1600 and $1493 \mathrm{~cm}^{-1}$. Oxygen containing chemical groups (C-O and $\mathrm{C}=\mathrm{O}$ ) are only present as weak absorption bands. Besides oxygen containing fragments from ethylene glycol, incorporation of oxygen atoms in the ppES films is also possible in the plasma volume due to the rich atomic oxygen environment, as revealed by plasma diagnosis using optical emission spectroscopy [8].

The broad band between $3600-3200 \mathrm{~cm}^{-1}$ is corresponding to $\mathrm{OH}$ groups which are incorporated in the ppES films (Fig. 2b). Methyl C-H groups, identified at 2930 and $2866 \mathrm{~cm}^{-1}$, are specific for both polystyrene and polyethylene glycol films and are visible in the FTIR 
spectrum of ppES at the same wavenumbers. Aromatic C-H stretching vibrations, identified at $3025 \mathrm{~cm}^{-1}$ and $3061 \mathrm{~cm}^{-1}$, are specific to polystyrene films. Therefore, the groups are only visible in the ppES and polystyrene spectra $[13,14]$.

\section{b. UV-Vis Spectra Analysis}

Most polymeric films are transparent in the visible and opaque in the UV domain. The UV-Vis analysis was performed in order to check the optical transparency of our plasma polymer films. Typical UV-Vis spectra of plasma polystyrene, polyethylene glycol and ppES films are shown in Fig. (3).

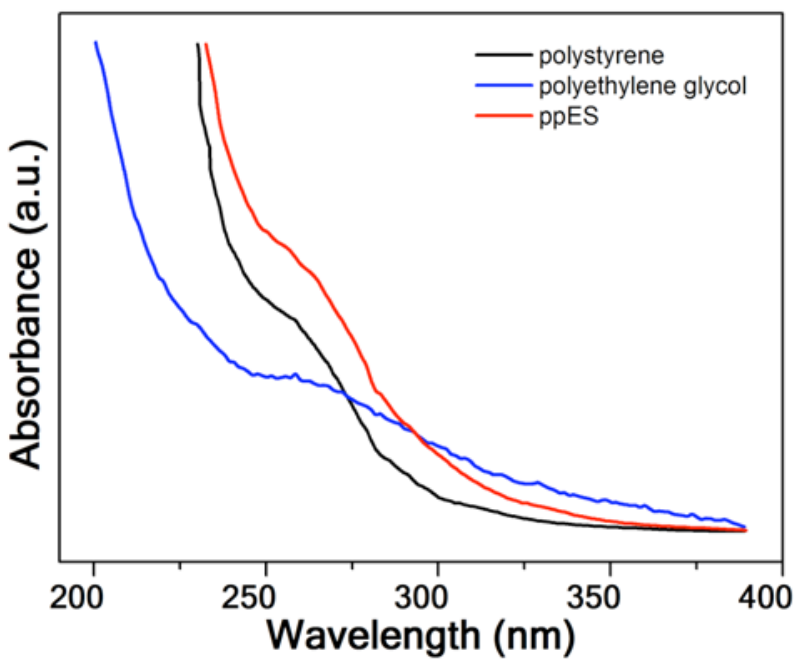

Fig. (3). UV-Vis spectra of the plasma polymerized films.

Appearance of an absorption band around $270 \mathrm{~nm}$ is common for complex molecular systems. The polystyrene films show a maximum of absorbance band between 250$280 \mathrm{~nm}$ which can be attributed to $\pi-\pi^{*}$ transition in aromatic ring and the same band is present in the UV-Vis spectrum of ppES films [15].

\section{c. XPS Analysis}

The XPS survey spectrum of the plasma copolymer polymer reveals the presence of carbon $(284.5 \mathrm{eV})$ and oxygen $(531.5 \mathrm{eV})$. The elemental concentrations were derived from the area of $\mathrm{C} 1 \mathrm{~s}$ and $\mathrm{O} 1 \mathrm{~s}$ peaks. The ppES films contain approximately $87.9 \%$ carbon and $12.1 \%$ oxygen. Detailed analysis of high resolution $\mathrm{C} 1 \mathrm{~s}$ and $\mathrm{O} 1 \mathrm{~s}$ peaks indicate the presence of multiple carbon and oxygen containing species.

Therefore, the $\mathrm{C} 1 \mathrm{~s}$ envelope can be deconvoluted into four components (Fig. 4) assigned to $\mathrm{C}-\mathrm{C} / \mathrm{C}=\mathrm{C} / \mathrm{C}-\mathrm{H}$ bonds (284.5 eV), C-O bonds (285.8 eV), C=O bonds $(286.7 \mathrm{eV})$ and the $\pi-\pi^{*}$ shake-up satellite $(291.3 \mathrm{eV})$ of the benzene rings [16-18].

The O1s peak (Fig. 5) is composed from two peaks corresponding to $\mathrm{C}-\mathrm{O}(532.1 \mathrm{eV})$ and $\mathrm{C}=\mathrm{O}(531.1 \mathrm{eV})$. These peaks contain the hydroxyl groups from ethylene glycol, which are incorporated in the copolymer volume. The concentration of chemical groups was calculated using the peak areas from the high resolution XPS spectra. In this way, it was estimated that the ppES films contains $75.8 \%$ of C$\mathrm{C} / \mathrm{C}=\mathrm{C}$ or $\mathrm{C}-\mathrm{H}$ groups, $14.1 \%$ of $\mathrm{C}-\mathrm{O}, 6 \%$ of $\mathrm{C}=\mathrm{O}$ and $4.1 \%$ of phenyl groups. The results of XPS analyses are in good agreement with those from FTIR analyses, which proves the presence of hydroxyl groups in the ppES films.

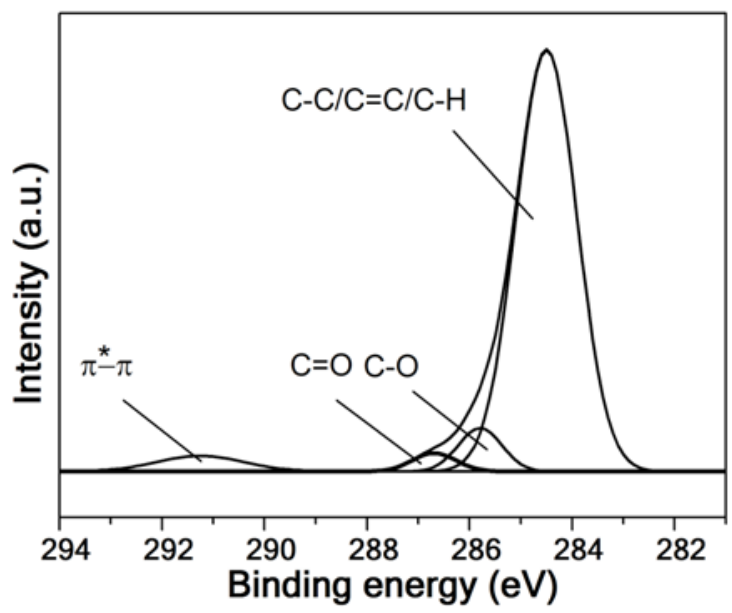

Fig. (4). Deconvolution of XPS spectrum corresponding to the C1s peak of ppES films.

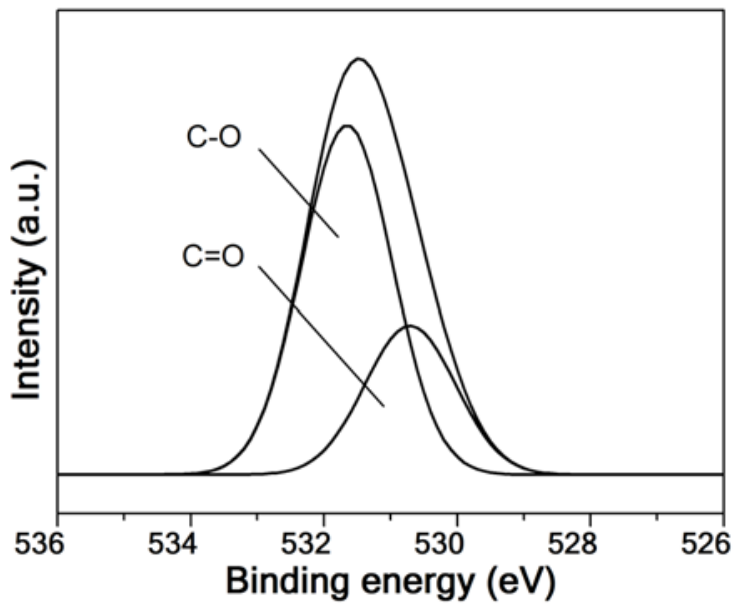

Fig. (5). Deconvolution of XPS spectrum corresponding to the O1s peak of ppES films.

\section{d. AFM Images}

The topography of ppES films is shown in a typical AFM image, $3 \mu \mathrm{m} \times 3 \mu \mathrm{m}$ (Fig. 6). The height data from this image

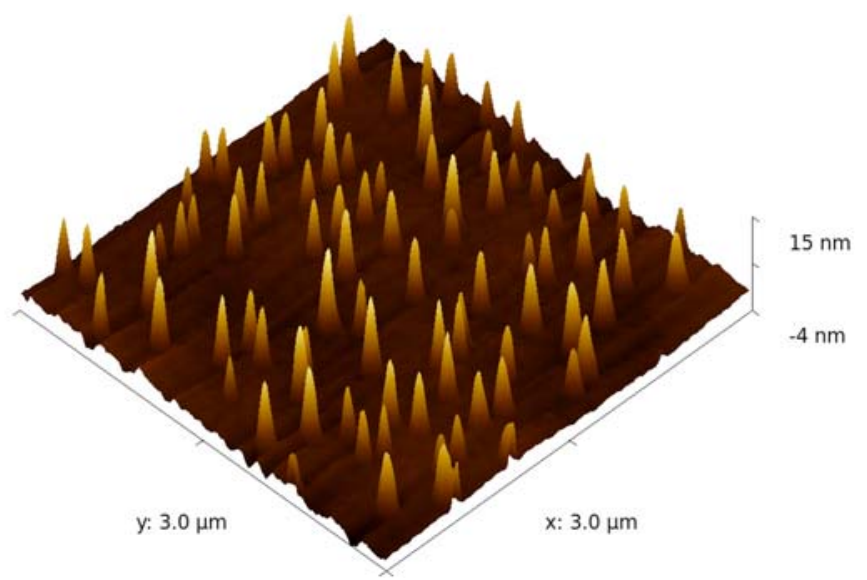

Fig. (6). AFM topography image of the ppES films. 


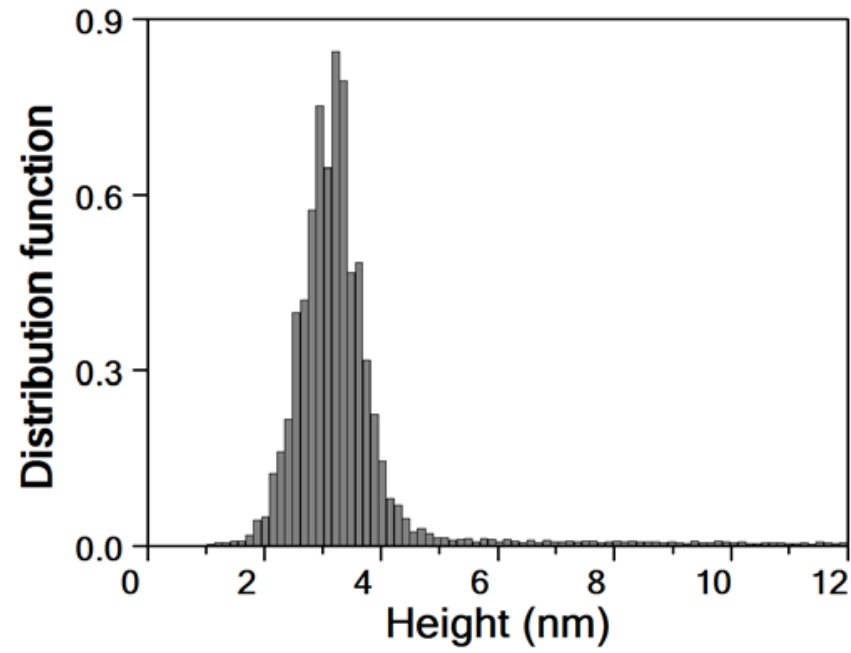

Fig. (7). Normalized height distribution function corresponding to data in Fig. (6).

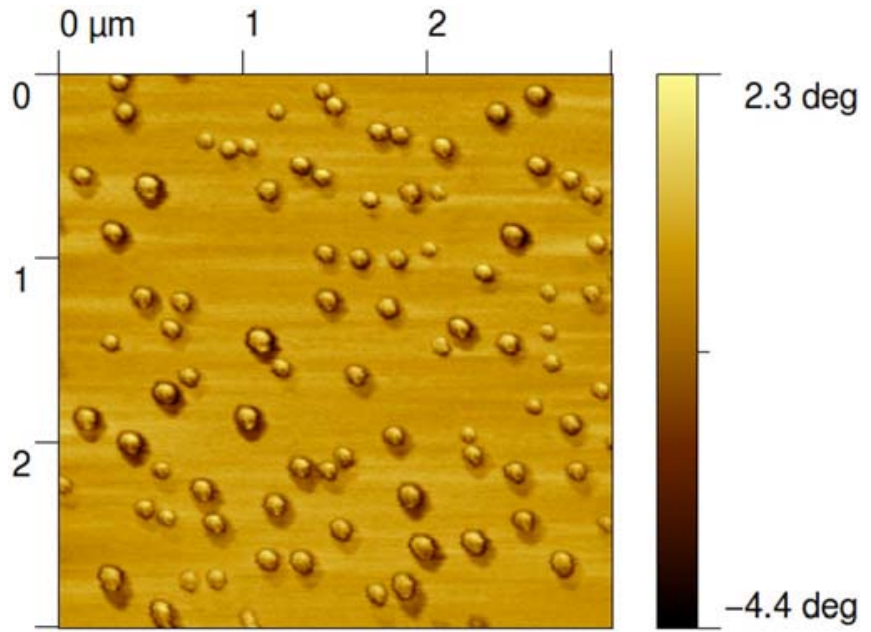

Fig. (8). Phase image corresponding to the topography image in Fig. (6).

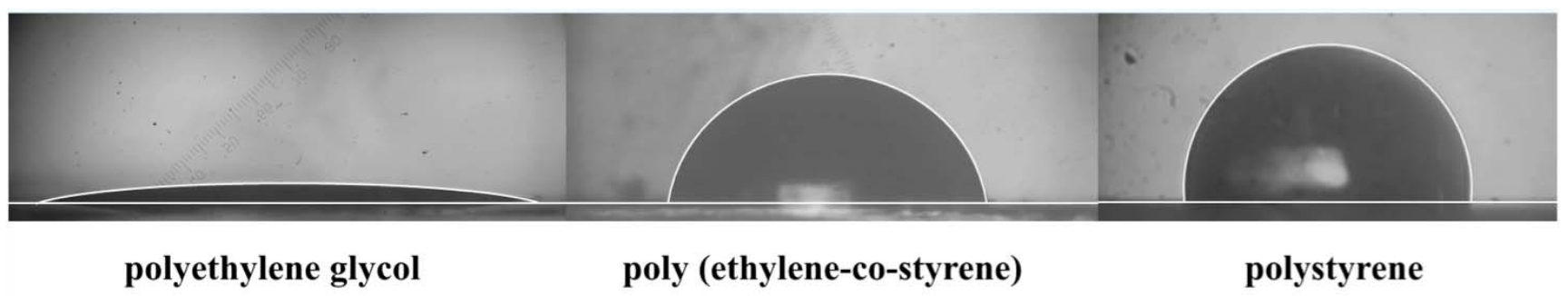

Fig. (9). Photos of $2 \mu \mathrm{L}$ water drops on plasma polystyrene, polyethylene glycol and poly (ethylene-co-styrene) surfaces.

were used to calculate the root mean square roughness $\left(\mathrm{R}_{\mathrm{rms}}\right)$ and a value of $1.6 \mathrm{~nm}$ was obtained. Well defined individual structures are randomly distributed at the surface. The height distribution function (Fig. 7) revealed a density of $\sim 10 \mu \mathrm{m}^{-2}$ and a height in the range of $1-12 \mathrm{~nm}$, with the average height being $3 \mathrm{~nm}$. A better representation of the peak contour can be seen in the AFM phase image, shown in Fig. (8).

\section{e. Wettability Measurements}

The water contact angle for ppES films is $\sim 70^{\circ}$ (Fig. 9) while the value for plasma polystyrene films is $\sim 90^{\circ}$ and for polyethylene glycol films $\sim 7^{\circ}$. These results show that the hydrophobic character of the plasma polystyrene films is reduced due to the hydroxyl groups from ethylene glycol.

\section{CONCLUSIONS}

Plasma copolymerized films were successfully deposited by plasma polymerization of styrene/ethylene glycol mixture in an atmospheric pressure discharge. The FTIR spectra show that the ppES films contain chemical groups from styrene and ethylene glycol molecules, including preserved hydroxyl groups from ethylene glycol. Wettability of polymerized films was studied and we observed that the water contact angle of ppES films is smaller than the one of polystyrene films, due to incorporation of hydroxyl groups. Therefore, our results prove that the ppES films are suitable to be tested as protein and cell resistant materials and can be considered as a solution for biomaterials surface coating.

\section{CONFLICT OF INTEREST}

The authors confirm that this article content has no conflict of interest.

\section{ACKNOWLEDGEMENTS}

This work was supported by CNCSIS-UEFISCSU, project number PNII - IDEI 384/2007-2010 and project POSDRU/88/1.5/S/47646.

\section{REFERENCES}

[1] Ademovic Z, Winther-Jensen B, Hou X, Kingshott P. Surface modification of PET films using pulsed AC plasma polymerization aimed at preventing protein adsorption. Plasma Process Polym 2005; 2 : 53-63.

[2] D'Sa RA, Meenan BJ. Chemical grafting of poly (ethylene glycol) methyl ether methacrylate onto polymer surfaces by atmospheric pressure plasma processing. Langmuir 2010; 26: 1894-903.

[3] Yasuda H. Plasma polymerization. London: Academic Press 1985.

[4] Inagaki N. Plasma surface modification and plasma polymerization. Lancaster: Technomic Publishing Company 1996.

[5] Hegemann D, Hossain MM, Korner E, Balazs DJ. Macroscopic description of plasma polymerization. Plasma Process Polym 2007; 4: 229-38.

[6] Yasuda H, Yu Q. Creation of polymerizable species in plasma polymerization. Plasma Chem Plasma Process 2004; 24: 325-51.

[7] Arefi F, Andre V, Motjtazer-Rahmati P, Amouroux J. Plasma polymerization and surface treatment of polymers. Pure Appl Chem 1992; 64: 715-23.

[8] Topala I, Asandulesa M, Spridon D, Dumitrascu N. Hydrophobic coatings obtained in atmospheric pressure plasma. IEEE Trans Plasma Sci 2009; 37: 946-50.

[9] Kingshott P, Wei J, Bagge-Ravn D, Gadegaard N, Gram L. Covalent attachement of poly (ethylene glycol) to surfaces, critical for reducing bacterial adhesion. Langmuir 2003; 19: 6912-21. 
[10] Bremmell KE, Kingshott P, Ademovic Z, Winther-Jensen B, Griesser HJ. Colloid probe AFM investigation of interactions between fibrinogen and PEG-like plasma polymer surfaces. Langmuir 2006; 22: 313-8.

[11] Zou XP, Kang ET, Neoh KG. Plasma-induced graft polymerization of poly (ethylene glycol) methyl ether methacrylate on $\mathrm{Si}(100)$ surfaces for reduction in protein adsorption and platelet adhesion. Plasmas Polym 2002; 7: 151-70.

[12] Liqiong $\mathrm{H}$, Qiang C, Yuanjing G. PEO-like functional films' polymerization in RF-PECVD. Plasma Sci Technol 2006; 5: 582-4.

[13] Guruvenket S, Rao GM, Komath M, Raichur AM. Plasma surface modification of polystyrene and polyethylene. Appl Surf Sci 2004; 236: $278-84$
[14] Bretagnol F, Lejeune M, Papadopoulou-Bouraoui A, et al. Fouling and non-fouling surfaces produced by plasma polymerization of ethylene oxide monomer. Acta Biomater 2006: 2: 165-72.

[15] Pawde SM, Parab SS. Spectroscopic and antimicrobial studies of polystyrene films under air plasma and $\mathrm{He}-\mathrm{Ne}$ laser treatment. Pramana J Phys 2008; 70: 935-48.

[16] Luo HL, Sheng J, Wan YZ. Plasma polymerization of styrene with carbon dioxide under glow discharge conditions. Appl Surf Sci 2007; 253: 5203-7.

[17] Sharma S, Johnson RW, Desai TA. XPS and AFM analysis of antifouling PEG interfaces for microfabricated silicon biosensors. Biosensors Bioelectron 2004; 20: 227-39.

[18] Silvan MM, Valsesia A, Gilliland D, Ceccone G, Rossi F. An evaluation of poly (ethylene-glycol) films stabilized by plasma and ion beam methods. Appl Surf Sci 2004; 235: 119-25.

(C) Asandulesa et al.; Licensee Bentham Open.

This is an open access article licensed under the terms of the Creative Commons Attribution Non-Commercial License (http://creativecommons.org/licenses/by-nc/3.0/) which permits unrestricted, non-commercial use, distribution and reproduction in any medium, provided the work is properly cited. 